\title{
Combined metformin-associated lactic acidosis and euglycemic ketoacidosis
}

Verena Schwetz (1); Florian Eisner (2); Gernot Schilcher (2); Kathrin Eller (3); Alice Lind (1); Johannes Plank (4); Thomas R. Pieber (1); Julia K. Mader (1); Philipp Eller (2)

on ondocrinology and Diabetology, (2) Intensive Care Unit, (3) Division of Nephrology (4) Division of Gastroenterology and Hepatology; Department of Internal Medicine, Medical University of Graz, Graz, Austria

Introduction and objectives: In metformin-associated lactic acidosis with renal dysfunction inhibition of hepatic gluconeogenesis by drug accumulation may aggravate fasting induced-ketoacidosis. We report the occurrence of metformin-associated lactic acidosis with concurrent euglycemic ketoacidosis in three patients with renal failure.

Cases: The first patient was a 79-year-old woman who suffered from chronic kidney disease stage IIIa after traumatic uninephrectomy, and had been on metformin therapy for over 10 years. She had been vomiting for two days, and was admitted to our intensive care unit with acute renal failure and lactic acidosis (see table 1). She also displayed elevated serum ketoacids of $7.4 \mathrm{mmol} / \mathrm{L}$ (see figure 1 ) at blood glucose level of $63 \mathrm{mg} / \mathrm{dL}$. Euglycemic ketoacidosis receded under treatment with intravenous glucose infusions.

The second patient was a 78-year-old woman who had been treated with metformin for T2DM and presented to our hospital with acute gastroenteritis. She displayed acute on chronic renal failure and lactic acidosis. Again we detected elevated serum ketoacids $(6.4 \mathrm{mmol} / \mathrm{L})$, even though blood glucose was in normal range $(76 \mathrm{mg} / \mathrm{dL})$. Ketoacidosis abated after infusion of glucose.

The third patient was a 71-year-old man who had been treated with metformin, canagliflozin and liraglutide for T2DM and presented with acute gastroenteritis. He displayed acute renal failure and lactic acidosis. The patient also displayed elevated serum ketoacids of $16 \mathrm{mmol} / \mathrm{L}$ and blood glucose of $152 \mathrm{mg} / \mathrm{dL}$. Ketoacidosis receded with intravenous glucose infusions.

Conclusions: The concurrent occurrence of euglycemic ketoacidosis in patients suffering from metformin-associated lactic acidosis poses a peculiar diagnostic and therapeutic challenge. This case series highlights the parallel occurrence of metformin-associated lactic acidosis and euglycemic ketoacidosis, the latter exceeding ketosis due to starvation, suggesting a metformin-triggered inhibition of gluconeogenesis. Affected patients benefit from glucose infusion counteracting suppressed hepatic gluconeogenesis.

Table 1: Patient characteristics and laboratory parameters at ICU admission.

Abbreviations: $\mathrm{T} 2 \mathrm{DM}=$ diabetes mellitus type 2

Correspondence: verena.schwetz@medunigraz.at
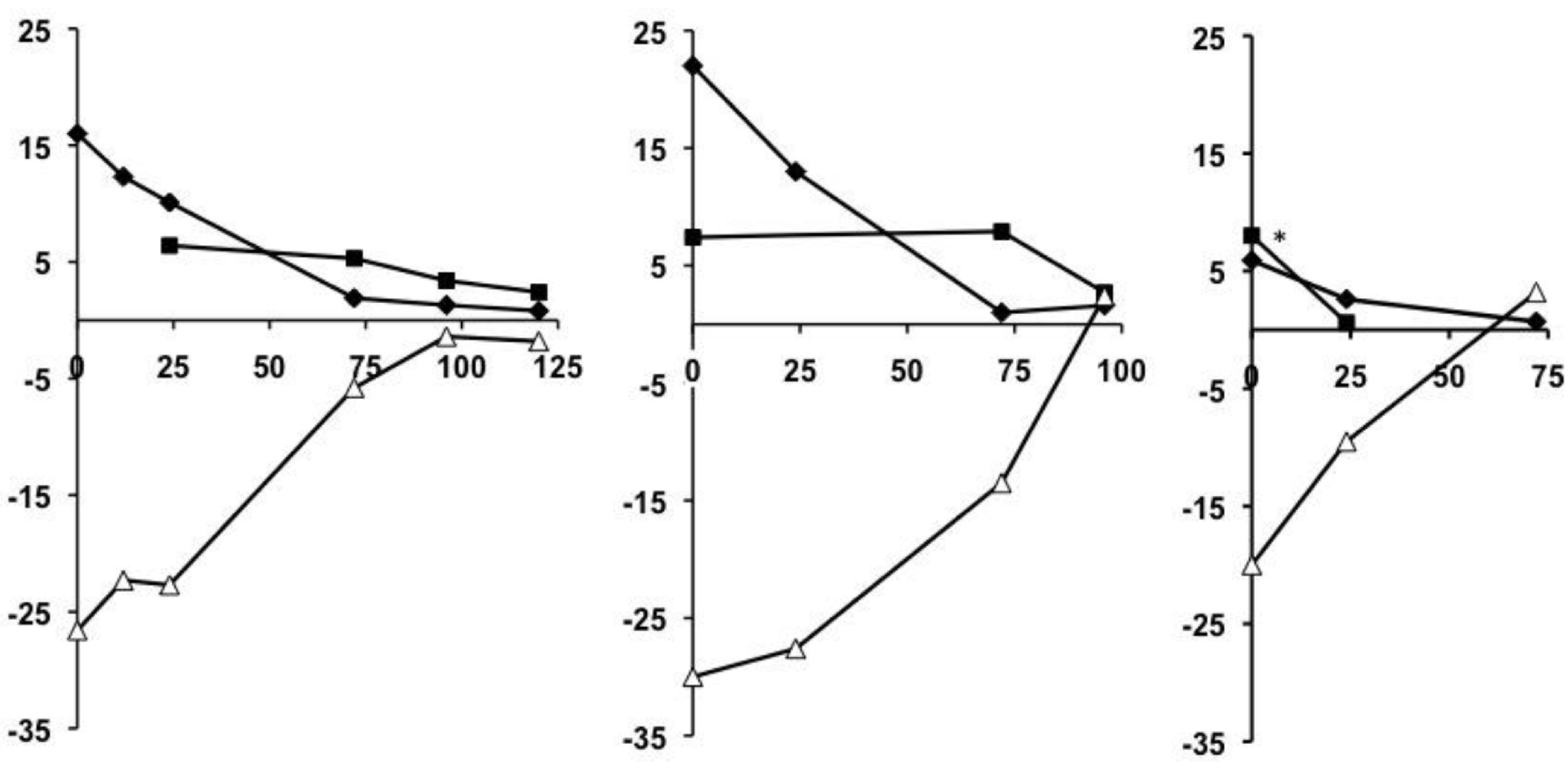

Figure 1: Metformin-associated lactic acidosis and euglycemic ketoacidosis in three critically ill patients

Blood gas analyses with serum levels of lactic acid (closed diamonds), ketoacids (closed squares), and base excess levels (open triangles) are plotted for patient $1(A)$, patient $2(B)$, and patient $3(\mathbf{C})$ as function of time $(h)$ on the abscissa. $*=$ Ketoacid levels exceeded $8 \mathrm{mmol} / \mathrm{L}$ in this patient, the true value was beyond the range of measurement.

\begin{tabular}{|c|c|c|c|}
\hline & Patient 1 (f) & Patient 2 (f) & Patient 3 (m) \\
\hline Age (years) & 79 & 78 & 71 \\
\hline $\begin{array}{l}\text { Diabetes } \\
\text { medication }\end{array}$ & metformin & metformin & $\begin{array}{l}\text { metformin, } \\
\text { canagliflozin, } \\
\text { liraglutide }\end{array}$ \\
\hline $\begin{array}{l}\text { Serum } \\
\text { creatinine } \\
\text { (mg/dL) }\end{array}$ & 9.0 & 9.0 & 13.6 \\
\hline $\mathrm{pH}$ & 6.89 & 6.8 & 7.21 \\
\hline $\begin{array}{l}\text { Lactic acid } \\
(\mathrm{mmol} / \mathrm{L})\end{array}$ & 22 & 14.7 & 5.9 \\
\hline $\begin{array}{l}\text { Serum } \\
\text { ketoacids } \\
(\mathrm{mmol} / \mathrm{L})\end{array}$ & 7.4 & 6.4 & 16 \\
\hline $\begin{array}{l}\text { Serum glucose } \\
(\mathrm{mg} / \mathrm{dL})\end{array}$ & 63 & 76 & 152 \\
\hline
\end{tabular}

